\title{
Transmission of bovine herpesvirus 1 within and between herds on an island with a BHV1 control programme
}

\author{
J. J. HAGE ${ }^{1 *}$, Y. H. SCHUKKEN ${ }^{2}$, H. SCHOLS ${ }^{3}$, M. A. MARIS-VELDHUIS ${ }^{4}$, \\ F. A. M. RIJSEWIJK ${ }^{4}$ AND C. H. L. KLAASSEN ${ }^{5}$ \\ ${ }^{1}$ Ruminant Health Department, Animal Health Service, P.O. Box 9, 7400 AA Deventer, The Netherlands \\ ${ }^{2}$ Department of Population Medicine and Diagnostic Sciences, College of Veterinary Medicine, \\ Cornell University, Ithaca, New York 14850, USA \\ ${ }^{3}$ Veterinary Practice Ameland, Vermaningspad 4, 9163 JD Nes, Ameland, The Netherlands \\ ${ }^{4}$ Division of Infectious Diseases and Food Chain Quality, ID-Lelystad, P.O. Box 65, 8200 AB Lelystad, \\ The Netherlands \\ ${ }^{5}$ Donsvlinder 22, 2317 KE Leiden, The Netherlands
}

(Accepted 9 January 2003)

\section{SUMMARY}

Transmission of bovine herpesvirus 1 (BHV1) within and between herds was studied on the island of Ameland, The Netherlands. There were 50 herds with 3300 head of cattle on the island. Herds were divided into three groups: (1) only containing seronegative cattle, (2) containing seronegative cattle and vaccinated seropositive cattle, and (3) containing only vaccinated cattle. All 23 herds in groups 1 and 2 were monitored. Three major outbreaks of BHV1 infections were observed due to the introduction of infectious cattle. Another major outbreak was most likely induced by reactivation of latent BHV1 in seropositive cattle. The basic reproduction ratio within these herds was estimated at least 4 . Only one of these outbreaks led to three secondary outbreaks in susceptible herds in which all cattle were seronegative. These outbreaks were most likely due to respectively, direct animal contact, human transmission, and aerogenic transmission. The basic reproduction ratio between herds in this study was estimated to be $0 \cdot 6$.

\section{INTRODUCTION}

Bovine herpesvirus 1 (BHV1) is an important pathogen in cattle all over the world. It can cause infectious bovine rhinotracheitis (IBR), infectious pustular vulvovaginitis (IPV), infectious pustular balanophostitis (IPB), abortion and fatal systemic infections in newborns [1-3]. Subclinical infections with BHV1 can also occur [4, 5].

After infection with BHV1, animals become latently infected in peripheral ganglia $[1,6]$ and

\footnotetext{
* Author for correspondence: Ruminant Health Department, Animal Health Service, P.O. Box 9, 7400 AA Deventer, The Netherlands.
}

develop antibodies against BHV1 that persist for at least 5.5 years [7]. After a period of stress BHV1 can be reactivated and re-excreted at the primary site of infection [6, 8].

Vaccination against BHV1 protects against clinical disease and reduces the duration and level of virus shedding after an intranasal challenge infection [9], in some cases to low or even undetectable levels [10]. Vaccination of seropositive cattle with an inactivated vaccine may lead to a considerable reduction in the amount of re-excreted virus after reactivation [11].

The basic reproduction ratio $\left(R_{0}\right)$ is a threshold value used to describe infection dynamics in a completely susceptible population. It is defined as the 
average number of secondary cases generated by one primary case in a wholly susceptible population of defined density [12, 13]. A disease will probably maintain itself within a population provided that the basic reproduction ratio, $R_{0}$, of the infection is greater than, or equal to, 1 . Infections which are characterized by high $R_{0}$ values will be more difficult to control than those with a low $R_{0}$ value.

After the introduction of BHV1 in a susceptible population the virus spreads rapidly, and in one study the $R_{0}$ of BHV1 within a herd ( $R_{0 \text {, within }}$ ) was estimated to be at least 7 [5]. The $R_{0}$ of BHV1 between herds $\left(R_{0, \text { between }}\right)$ has not been studied yet. Eradication will occur when both reproduction ratios, $R_{0}$, within and $R_{0 \text {, between }}$, are less than 1 , or, when $R_{0}$, within is greater

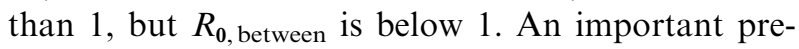
requisite for this is that the virus does not persist on infected farms. $R_{0, \text { between }}$ depends on $R_{0 \text {, within }}$, on the contact rate between herds, but also on the herd size [14]. $R_{0, \text { within }}$ and $R_{0, \text { between }}$ can be reduced by vaccination of a proportion of the population [15], and by eliminating or reducing contacts between individuals ( $\left.R_{0, \text { within }}\right)$ or herds $\left(R_{0, \text { between }}\right)$ [16]. Knowledge of within and between herd transmission of BHV1 is crucial in eradication programmes.

The objective of this study is to estimate the transmission of BHV1 within herds and between herds during outbreaks of infections. Because we ran a BHV1 control programme on an island, we were in the position to monitor the outbreaks closely, and to trace the origin of the infections.

\section{MATERIALS AND METHODS}

\section{Island and herds}

This study, performed on the island of Ameland, The Netherlands, started in November 1992 and ended November 1996. The island harbours approximately 50 cattle farms with 3300 head of cattle (Fig. 1). All cattle farmers on the island participated in this study on a voluntary basis.

Because of intermittent outbreaks of BHV1 that first started in 1982, on 22 farms cattle had been vaccinated intranasally against BHV1, using a temperaturesensitive (ts) mutant-vaccine (Tracherine ${ }^{\mathrm{R}}$, Pfizer Animal Health, Lincoln, NE, USA), once a year for 1 or more years in the following 9 years.

In 1990 and 1991 cattle on five farms were vaccinated with this ts-mutant BHV1 vaccine. This tsmutant vaccine is known for its ability to go latent after intranasal administration and to be reactivatable [17].

\section{BHV1 control programme}

At the start of the study, blood samples from all cattle on the island were collected and screened for antibodies against BHV1, using a gB-blocking ELISA [18] in which sera were examined undiluted. As maternal antibodies can be detected up to 9 months of age [19] and because the gB-ELISA we used is very sensitive [18], seropositive cattle younger than 10 months of age were considered to be seropositive due to maternal antibodies and most likely not to be latently infected with BHV1. All seropositive cattle older than 10 months of age were considered to be latently infected with BHV1.

Farms were divided into three groups (Table 1):

(1) Herds in which all cattle older than 10 months of age were seronegative; in these herds no cattle were vaccinated (group 1).

(2) Herds in which most of the cattle older than 10 months of age were seronegative. The seropositive cattle older than 10 months of age were vaccinated twice a year, at a 5- to 7-month interval, with a BHV1 subunit vaccine containing all the glycoproteins of BHV1 (Ibépur ${ }^{\mathrm{R}}$, Merial, Lyon, France) (group 2).

(3) Herds in which all cattle were vaccinated against BHV1 twice a year, at a 5- to 7-month interval (group 3). All cattle in this group were vaccinated intranasally with a ts-mutant BHV1 vaccine [20] in November 1992, March 1993, and November 1993. From March 1994 (with a booster vaccination given in April 1994), these animals were vaccinated twice a year with a BHV1 $\mathrm{gD}$ subunit vaccine. The principle of this experimental BHV1 gD subunit vaccine (Pfizer Animal Health) was first described by Van Drunen Littel-van den Hurk et al. [9].

All farmers were asked not to purchase cattle from the mainland. Nevertheless, if farmers wanted to bring in cattle from the mainland, they were asked to place these animals in quarantine for 2 weeks, after which period blood samples from these animals were collected and checked for antibodies against BHV1. If cattle older than 10 months of age turned out to be seropositive, they were removed or vaccinated, depending on the current strategy on the farm. During 

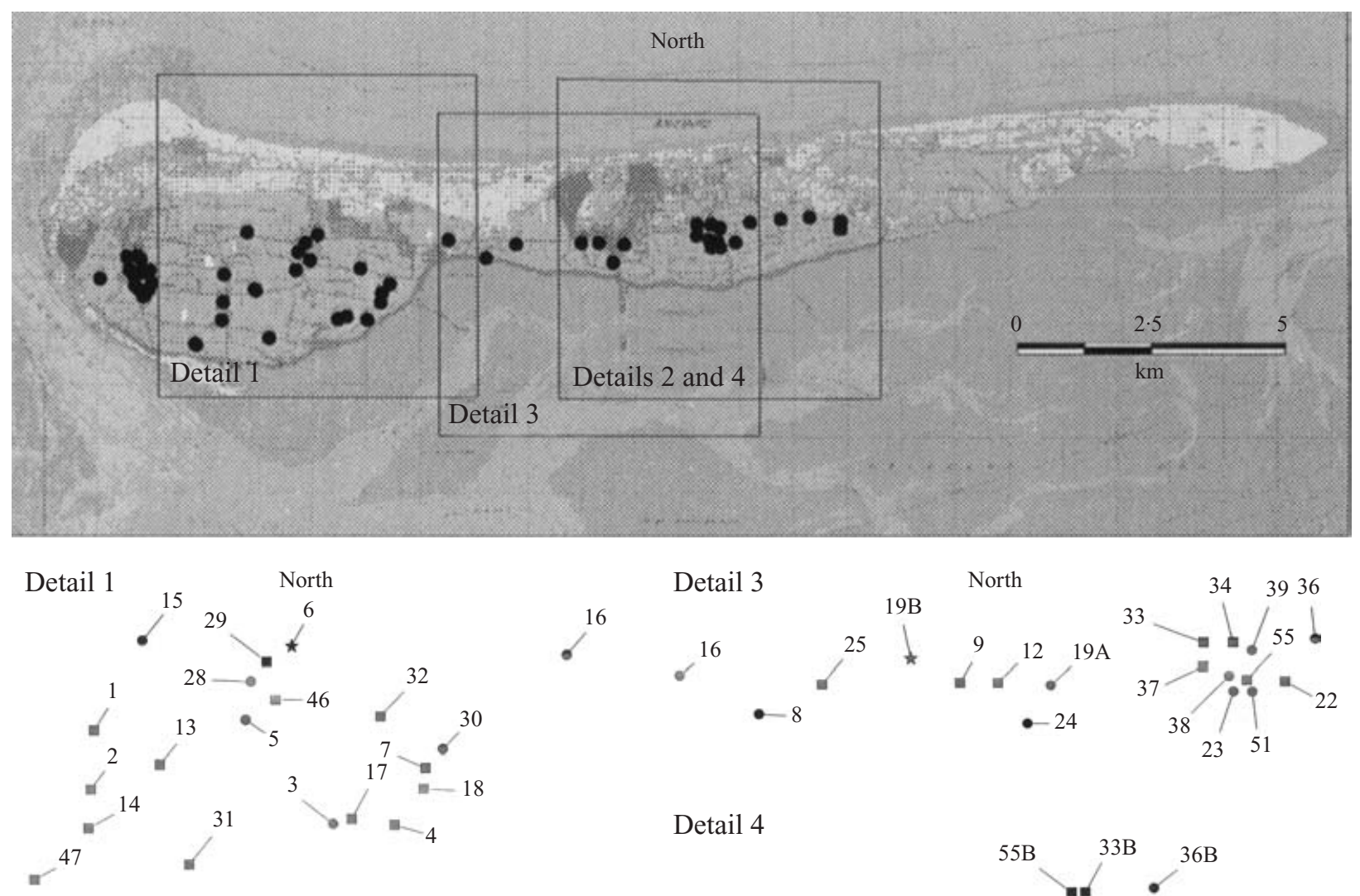

Detail 4
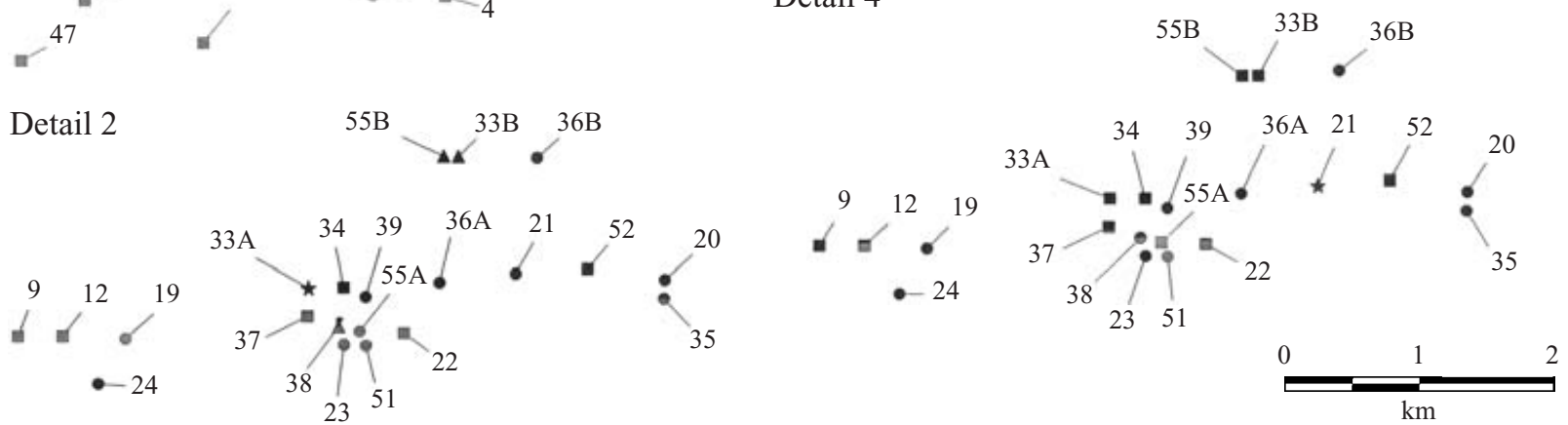

Fig. 1. Main figure: topographic map of the island Ameland, and location of all cattle farms. $\bullet$, location of farm. Details of topographic map of the island Ameland. (a) All herds at the time of BHV1 outbreak 1A within a radius of $3 \mathrm{~km}$ from herd 6 with an introduction of BHV1. (b) All herds at the time of BHV1 outbreak 1B within a radius of $3 \mathrm{~km}$ from herd 33A with an introduction of BHV1. (c) All herds at the time of BHV1 outbreak 2 within a radius of $3 \mathrm{~km}$ from herd 19B with an introduction of BHV1. (d) All herds at the time of BHV1 outbreak 3 within a radius of $3 \mathrm{~km}$ from herd 21 with an introduction of BHV1. $\star$, herd with BHV1 introduction; $\triangle$, infected herd; $\boldsymbol{\bullet}$, susceptible herd; $\mathbf{\square}$, vaccinated herd.

the study farms were allowed to switch from one group to another.

\section{Monitoring programme}

During the study, all cattle of groups 1 and 2 were screened for antibodies against BHV1, using a gBblocking ELISA [18] in which sera are examined undiluted, in November and March, the beginning and end of the housing period.

The gD subunit vaccine does not induce antibodies against BHV1-gB. Therefore, in November 1996 all cattle of group 3 were screened for antibodies against BHV1-gB.

We monitored animal movements on a weekly basis to the farms by making use of the Dutch cattle identification and registration system.

\section{Outbreak of BHV1}

When an outbreak of BHV1 was suspected in a herd, nasal swabs were taken for virus isolation or polymerase chain reaction (PCR) and paired blood samples were taken from a representative number of cattle 
Table 1. Characteristics of farms in each group in 1992 and 1996

\begin{tabular}{|c|c|c|c|c|c|c|}
\hline & \multicolumn{2}{|c|}{$\begin{array}{l}\text { Group } 1 \\
\text { BHV1-free }\end{array}$} & \multicolumn{2}{|c|}{$\begin{array}{l}\text { Group } 2 \\
\text { vaccinated } \\
\text { seropositive }\end{array}$} & \multicolumn{2}{|c|}{$\begin{array}{l}\text { Group } 3 \\
\text { vaccinated } \\
\text { all cattle }\end{array}$} \\
\hline & 1992 & 1996 & 1992 & 1996 & 1992 & 1996 \\
\hline Number of farms & 12 & 11 & 11 & 10 & 27 & 23 \\
\hline Total number of cattle & 469 & 621 & 827 & 719 & 1924 & 1792 \\
\hline Range cattle on farms & 6-82 & $6-160$ & $38-178$ & 49-22 & $1-239$ & $2-240$ \\
\hline Average cattle on farms & 39 & 46 & 75 & 72 & 71 & 78 \\
\hline Dairy farms & 7 & 7 & 10 & 8 & 16 & 15 \\
\hline Non-dairy farms & 5 & 4 & 1 & 2 & 11 & 8 \\
\hline
\end{tabular}

in that herd. Precautions were taken by the practitioner to prevent BHV1 transmission when herds were visited during their infectious period. The average infectious period was estimated to be approximately 7 weeks [5]. The start of an outbreak was estimated from clinical signs and laboratory findings. Subclinical outbreaks were diagnosed throughout the monitoring programme.

\section{BHV1 determination}

To determine the presence of BHV1 in nasal swabs, the virus was either isolated and typed by using an indirect immunofluorescence test, or a PCR assay was performed. These methods have previously been described by Hage et al. [21].

\section{DNA isolation and restriction enzyme analysis}

Restriction enzyme analysis (REA) was performed on DNA from three BHV1 isolates obtained from three cattle from herd 33A $(7245,8719$ and 8951) and from six isolates from farm $38(1272,4793,8705,9010,9019$ and 9266), on the Dutch field isolate Lam [22], on the IPV strain 61169, and on the ts-strain of BHV1 (RBL 106).

Virus was propagated and purified by using the procedure described by Van Oirschot et al. [23]. To isolate DNA, virus was lysed with sodium-dodecylsulphate (SDS) and proteinase $\mathrm{K}$ at $37^{\circ} \mathrm{C}$ for $1 \mathrm{~h}$. DNA was extracted from this lysate by using a standard phenol extraction method [24]. The extracted DNA was precipitated with ethanol and the pellet was resuspended in $50 \mu \mathrm{TE}(10 \mathrm{~mm}$ Tris, $1 \mathrm{~mm}$ EDTA, $\mathrm{pH} 7 \cdot 4)$. Between 0.5 and $1 \mu \mathrm{g}$ of genomic DNA was used for REA with HindIII and EcoRV. The restriction enzymes were used under conditions recommended by the manufacturer (Boehringer-Mannheim). The restriction enzyme fragments were separated by electrophoresis on a $0.5 \%$ agarose gel (low electroendosmosis, electrophoretic grade; BoehringerMannheim) in TAE (40 mm Tris-acetate and $1 \mathrm{~mm}$ EDTA, $\mathrm{pH}$ 8.0). The gels were stained with ethidium bromide and photographed, using a UV transilluminator.

\section{Estimation of the basic reproduction ratio}

The basic reproduction ratio within a herd $\left(R_{0, \text { within }}\right)$ was estimated by using a martingale estimator as described by Becker [13] and previously described by Hage et al. [5]. Estimation is based on the final magnitude of the outbreak. $R_{0, \text { within }}$ is then given by:

$R_{0, \text { within }}=\frac{S_{0}}{\left(P_{r}-Z\right)} \sum_{x=S_{r}+1}^{S_{0}} \frac{1}{X}$,

where $S_{0}$ is the number of susceptible cattle at the start of an outbreak, $S_{r}$ is the number of susceptible cattle at the end of the outbreak, $P_{r}$ is number of cattle that have been infectious, and $Z$ is the number of infectious cattle in the last generation. When $Z$ was unknown it was set equal to zero.

The basic reproduction ratio for between-herd transmission of BHV1 was estimated by using a chain-binomial model [13]. The probability of a given chain of infections is given by:

$p r\left(i_{0} \rightarrow i_{1} \rightarrow \cdots \rightarrow i_{r}\right)=\frac{S_{0} !}{i_{1} ! i_{2} ! \cdots i_{r} ! S_{r} !} \prod_{t=0}^{r} p_{i_{t}}^{i_{t}+1} q_{i_{t}}^{S_{t}-1}$,

where $t$ is the number of generations, $t=0,1,2, \ldots, r, i$ is the number of infectious herds, and $q_{i}$ is the probability that a susceptible herd escapes infection when exposed to $i$ infective herds, and $p_{i}=1-q_{i}$. For the present analysis, a Reed-Frost model was assumed, hence $q_{i}$ equals $q^{i}$. 


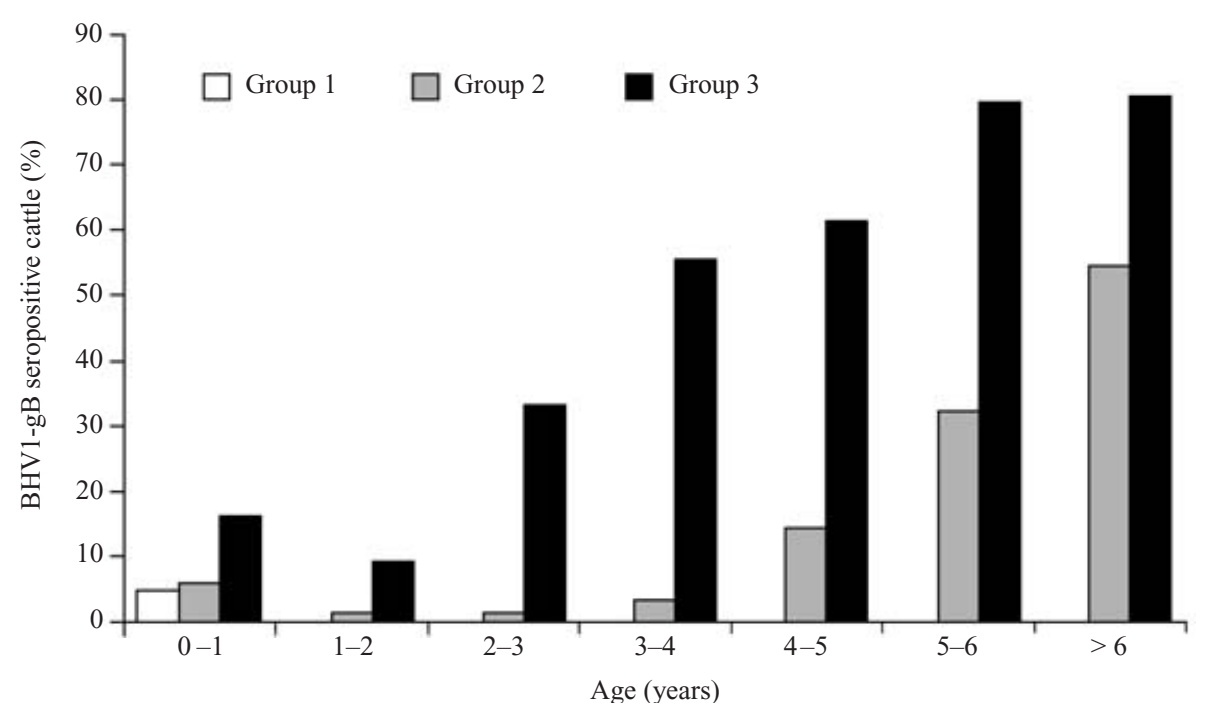

Fig. 2. Prevalence of BHV1-gB seropositive cattle per age category in the three vaccination groups before the start of the study.

The estimated chain probabilities were then compared to the observed probabilities, and $p$ was estimated. The basic reproduction ratio between herds $\left(R_{0, \text { between }}\right)$ was then calculated as $p * N$, where $N$ is the number of herds in the outbreak area. Standard error estimates were done as described by Becker [13].

For the analysis, we assumed that herds with unvaccinated BHV1-gB-seronegative cattle that were located within a radius of $3 \mathrm{~km}$ around the initial infectious farm were susceptible to infection. This area was chosen to reflect current European contagious disease strategies, by which after diagnosis of an outbreak on a farm, a $3-\mathrm{km}$ zone around that farm is established in which animal movements are prohibited. The vaccinated herds in group 3 were considered to be not susceptible to BHV1 infection. A high proportion of the cattle of these herds were seropositive for BHV1-gB. Contacts between farms were thought to take place through direct exchange of people, animals and materials. Aerogenic transmission of virus was considered possible. Contacts between farms were not known, but it was assumed that these contacts occurred randomly.

\section{RESULTS}

\section{Dynamics of BHV1 prevalence during the study}

The characteristics of the farms in each group in 1992 and 1996 are shown in Table 1 . The prevalence of BHV1-gB-seropositive cattle per age group for the three groups before the start of this study is shown in Figure 2.
In group 1 only a few seropositive calves were present (most likely due to maternal antibodies of culled seropositive dams), in group 2 there was evidence of a previous infection (approximately 4 years ago), and in group 3 a large number of animals aged 3 years and older were seropositive for antibodies against BHV1-gB.

Between November 1992 and November 1994 BHV1 did not circulate in the 23 farms of groups 1 and 2. In fact, the total number of seropositive cattle older than 10 months in these herds decreased from 90 to 44 (Fig. 3). Between November 1993 and November 1994 seven seropositive cattle were purchased by farms initially in group 1 .

Up to November 1993, all cattle of herds in group 3 were intranasally vaccinated with the ts strain. In November 1996, almost all cattle older than 3 years in the herds of group 3 were seropositive for antibodies against $\mathrm{BHV} 1-\mathrm{gB}$, whereas cattle aged between 6 months and 3 years were seronegative for BHV1-gB.

The number of herds in which BHV1 was introduced during the course of the study is shown in Figure 4. As a result of virus introduction there was a sharp increase in the number of seropositive cattle in groups 1 and 2 (Fig. 3). The total number of BHV1free herds in 1992 remained equal to the number in 1996 (Table 2).

\section{BHV1 outbreaks within herds}

A total of 4 outbreaks, affecting 7 herds, were observed during the 4-year observation period (Fig. 4). 


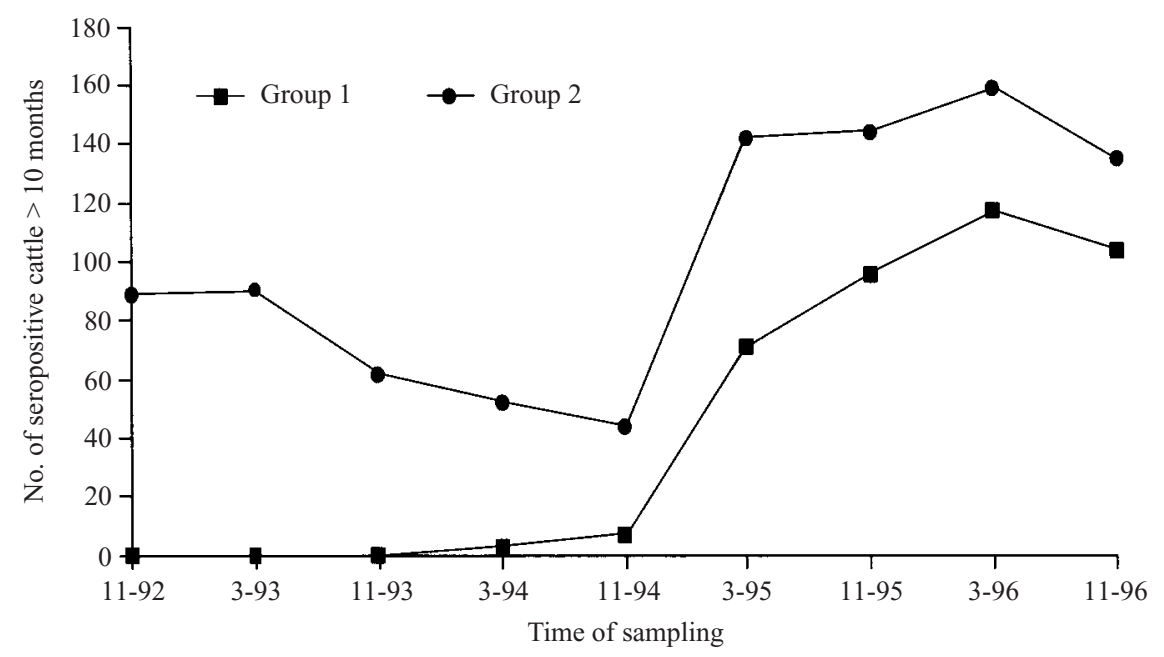

Fig. 3. Number of BHV1-gB seropositive cattle ( $>10$ months) on farms that were initially in group 1 or 2 during the course of the study.

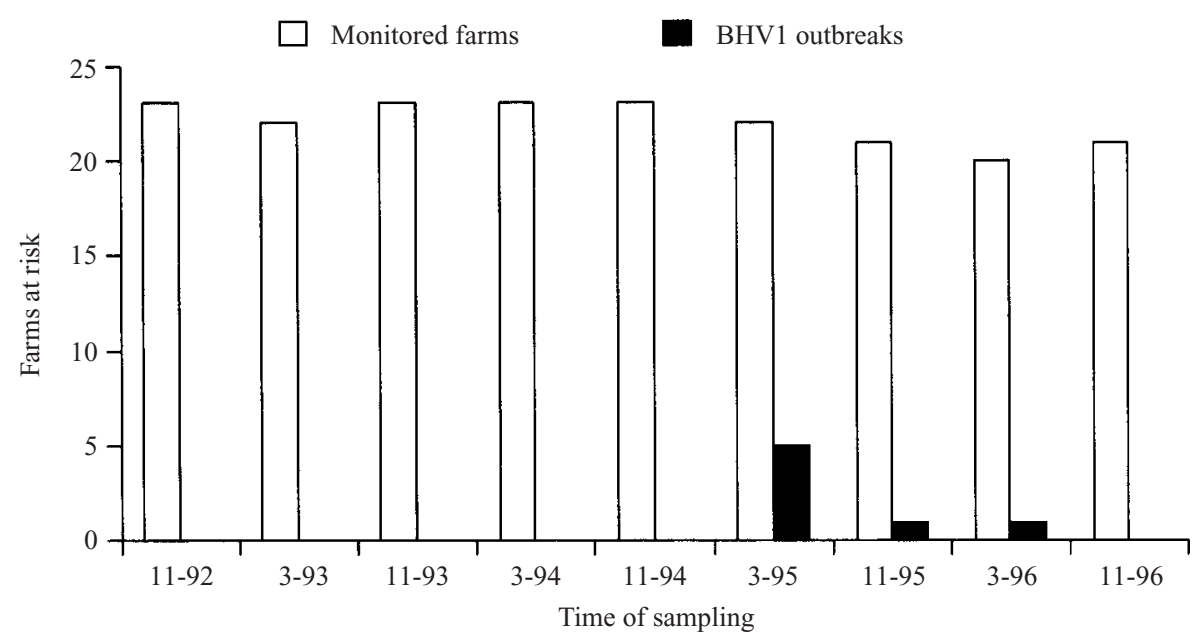

Fig. 4. Number of farms with BHV1-seronegative cattle (groups 1 and 2) during the study, and the number of herds with BHV1 outbreaks.

The first 2 outbreaks were related. On 22 December 1994, 3 cattle from 3 different herds from the mainland were shipped to the island in 1 truck and delivered to 2 different farms.

\section{Outbreak $1 A$}

Two cattle from the truck were placed on farm 6 (group 2, 57 cattle, 3 seropositive older than 10 months of age, loose-housing, intensive contacts), without first being put in quarantine (Fig. 1a).

On 28 December 1994, the two cattle did not have detectable antibodies against BHV1-gB, but by 12 January 1995, one animal had developed antibodies against BHV1-gB.
Severe clinical signs of BHV1 were seen in almost all cattle on this farm between 2 January and 7 February 1995. The diagnosis was confirmed by PCR on nasal swabs. Eventually, seven cows died of pneumonia complicated by Pasteurella spp. All animals had antibodies against BHV1-gB on 7 February 1995.

\section{Outbreak $1 B$}

The third animal from the truck was placed in barn 1 of herd 33A on 22 December 1994, without first being put in quarantine (Fig. $1 b$ ). Herd 33A (58 cows, tiestall, divided over 3 closely related barns: 1, 2 and 3 ) was in group 1. In barn 1, 10 cattle were housed and only mild clinical signs of IBR were seen from 
Table 2. Number of farms from the initial groups in 1992 related to their present group in 1996

\begin{tabular}{rlllll}
\hline \hline & & \multicolumn{2}{l}{ To 1996} \\
\cline { 3 - 5 } & Group/ & 1 & 2 & 3 & Stopped \\
\hline From & 1 & 6 & 4 & 1 & 1 \\
1992 & 2 & 5 & 6 & 0 & 0 \\
& 3 & 0 & 0 & 22 & 5 \\
\hline \hline
\end{tabular}

5 January 1995. On 15 January 1995, 2 cattle from barn 1 were moved to barn 3 ( 31 cows and 3 calves). Between 31 January and 28 February 1995, there were severe signs of IBR in cows in barn 3. BHV1 was isolated from 3 out of 4 nasal swabs from cattle in barn 3 on 1 February 1995.

On 6 February 1995, all 14 cattle in barn 2 were seronegative for BHV1.

On 9 February 1995 virus was isolated from four nasal swabs from cattle in barn 2. On 27 March 1995, all cattle of herd 33A were seropositive for BHV1-gB.

Herd 33B (group 1, 8 cattle) has been kept outside on pasture since November 1994. In an attempt to prevent transmission of BHV1 to this herd, hygiene measures were taken (changing overalls and boots) as soon as the clinical signs were visible on 31 January 1995.

\section{Outbreak 2}

In the summer of 1995, cattle on farm 19 (group 1) were kept in two herds, 19A and 19B. Herd 19A (37 cattle) was housed on the farm, whereas herd 19B (31 cattle) was kept on pasture (Fig. 1c). From 1 August 1995, cattle of herd 19B did not have any direct contact with cattle from other herds. On 17 August 1995, one heifer was brought in from the mainland and added to herd 19B without first being put in quarantine. No clinical signs of BHV1 were observed, but on 27 November 1995, all cattle of herd 19B were seropositive for antibodies against BHV1gB. All initially seronegative cattle of herd 19A remained seronegative.

\section{Outbreak 3}

One BHV1 outbreak started sometime between December 1995 and March 1996 on farm 21 (group 2, 44 cattle) (Fig. 1d). On 26 November 1995, farm 21 consisted of 34 seronegative cattle and 7 seropositive cattle older than 10 months of age. Clinical signs indicative of mild IBR infections were first seen in young cattle on 15 March 1996. No nasal swabs or blood samples were taken. On 27 March 1996, all initially seronegative cattle of farm 21 had antibodies against BHV1-gB.

Assuming a slow spread of BHV1 due to the tiestall housing system, it is possible that the first seronegative cattle were already infected in the beginning of February 1996. In this period all cattle were housed in a tie-stall and five calves younger than 2 weeks of age were purchased. One calf was seronegative 3 weeks after introduction to the farm, and the other four calves had been born on farm 52 (group 3, 125 cattle). Screening of blood samples from cattle on farm 52 in November 1996 showed no seropositive cattle older than 10 months and younger than 3 years of age, indicating that BHV1 had not circulated on farm 52 in the last 3 years. Therefore, it seemed unlikely that these five purchased calves introduced the BHV1 infection to farm 21. The serological results of other monitored farms in March 1996 indicated that there had been no virus circulation since November 1995. Therefore, transmission of BHV1 from other farms on the island to farm 21 is very unlikely. Reactivation and subsequent re-excretion of BHV1 by latently infected cattle in the herd could have been the cause of this BHV1 outbreak.

\section{Between-herd outbreaks}

The infection chains of between-herd infections are shown in Table 3.

\section{Outbreak $1 A$}

The introduction of BHV1 in December 1994 by three animals that were divided over herd 6 and herd 33A led to two outbreaks of BHV1 infection: outbreak 1A and outbreak $1 \mathrm{~B}$.

Cattle of herd 6 (outbreak 1A) had no contact with cattle from other herds. The farmer did not visit other farms during the infectious period of his herd.

Two farmers of group 2 herds handled cattle from herd 6 during the infectious period of this herd. There were no BHV1-gB seroconversions at the end of March 1995 in their herds. There were no other visitors to the herd during the infectious period of herd 6 . In a radius of $3 \mathrm{~km}$ from herd 6 there were no seroconversions in susceptible herds. We concluded that no other herds were infected with BHV1 by this herd (Table 3, Fig. 1a). 
Table 3. Characteristics of BHVI outbreaks

\begin{tabular}{lllll}
\hline \hline Outbreak & $\begin{array}{l}\text { Number of } \\
\text { introductions }\end{array}$ & $\begin{array}{l}\text { Infection } \\
\text { chain* }\end{array}$ & $\begin{array}{l}\text { Number of } \\
\text { susceptible } \\
\text { herds within } \\
\text { range } 3 \mathrm{~km} \dagger\end{array}$ & $\begin{array}{l}\text { Total number of } \\
\text { herds within } \\
\text { range } 3 \mathrm{~km} \dagger\end{array}$ \\
\hline $1 \mathrm{a}$ & 1 & $1-0$ & 6 & 20 \\
$1 \mathrm{~b}$ & 1 & $1-2-1$ & 14 & 21 \\
2 & 1 & $1-0$ & 10 & 19 \\
3 & 1 & $1-0$ & 10 & 21 \\
\hline \hline
\end{tabular}

* Outbreaks of BHV1 infections in herds caused by the former infected herds.

$\dagger$ From the first infected herd from an infection chain.

\section{Outbreak $1 B$}

Herd 33B (group 1, 8 cattle) was kept on pasture $1 \mathrm{~km}$ north-east of herd 33A (outbreak 1B, Fig. 1b). The farmer of herd 33A visited herd 33B several times a week to feed these cattle. Cattle of herd 33B did not show clinical signs of BHV1 infection, yet on 27 March 1995, all cattle of herd 33B had antibodies against BHV1-gB.

Herd 55B (group 1, 7 cattle) was kept on pasture, next to the pasture grazed by herd 33B. The cattle of the two herds were separated by a barbed wire fence, and thus direct nose-to-nose contacts were possible. On 27 March 1995, all cattle of herd 55B had antibodies against BHV1. At that time (and November 1995) no seroconversion was observed in herd 55A (group 1, 38 cattle).

Herd 38 (group 2, 60 seronegative cattle, tie-stall, 1 seropositive cow was kept at pasture) is located $250 \mathrm{~m}$ south-east of herd 33A. The first clinical signs of an IBR infection were seen in 1 cow on 28 February 1995; at that time 4 seronegative cows had fever. On 1 March 1995, 7 cows had fever and BHV1 was isolated from nasal swabs taken from 4 cows.

On 27 March 1995, 50 cattle had seroconverted to BHV1.

All initially seronegative cattle had been housed indoors since January 1995 and no visitors had visited the cattle in the month prior to the outbreak.

REA was performed on DNA from three and six BHV1 isolates obtained from herds 33A and 38, respectively. DNA-REA showed that the isolates of herd 33A (7245, 8719 and 8951) were all BHV1.1 (IBR-like) but their fragment patterns were different from each other. The isolates of herd 38 (1272, 4793, $8705,9010,9019$ and 9266) and one isolate of herd 33A (7245) were all BHV1.1 and their DNA fragment patterns were not different (Fig. 5). We concluded that herd 38 was infected by herd 33A.
In a radius of $3 \mathrm{~km}$ from herd $33 \mathrm{~A}$ there were no seroconversions in other susceptible herds, where most of the cattle were seronegative. We concluded that no other herds were infected with BHV1 by this herd (Table 3, Fig. 1b).

\section{Outbreak 2}

Herd 19B (group 1, 31 cattle) (Fig. 1c) was kept at pasture and animals could come in direct contact with animals of herd 24B (group 1, 10 cattle) until 1 August 1995. On 1 August 1995, herd 24B was moved to another pasture.

On 27 November 1995, all cattle of herd 24 were seronegative for BHV1.

In a radius of $3 \mathrm{~km}$ from herd $19 \mathrm{~B}$ there were no seroconversions in other susceptible herds. We concluded that no other herds were infected with BHV1 by this herd (Table 3, Fig. 1c).

\section{Outbreak 3}

During the infectious period all cattle of herd 21 were housed in a tie-stall. In a radius of $3 \mathrm{~km}$ from herd 21 there were no seroconversions in other susceptible herds in March and November 1996. We concluded that no other herds were infected with BHV1 by this herd (Table 3, Fig. 1d).

\section{Estimation of within and between-herd reproduction ratio}

In all herds, virus introduction led to a major outbreak. Estimates of the within-herd reproduction ratio were $4 \cdot 6,4 \cdot 7,4 \cdot 0$ and $4 \cdot 1$ for outbreaks $1 \mathrm{~A}, 1 \mathrm{~B}$, 2 and 3 , respectively.

Between-herd transmission of BHV1 was estimated from three chains where, after the initial case, no further farms were infected, and one case in which first two herds and then one herd were infected (Table 3). 

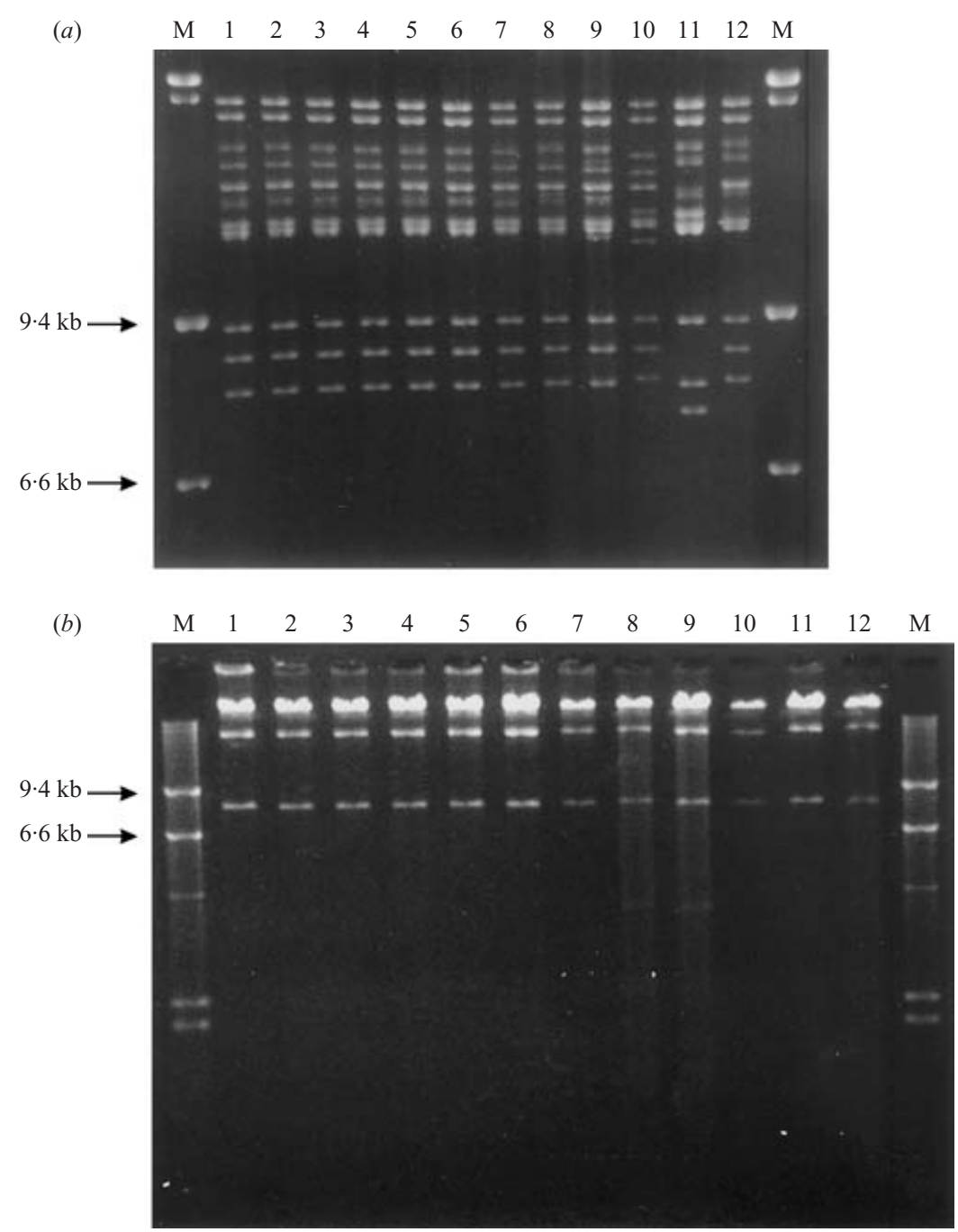

Fig. 5. DNA restriction enzyme analysis of the genomes of three BHV1 isolates of herd 33A and six BHV1 isolates of herd 38. (a) In lanes M phage lambda DNAs, digested with restriction enzyme HindIII, have been separated as markers. In lanes 1-6 HindIII digests of the genomic DNAs of the six BHV1 isolates from farm 38 have been separated (1272a , 4793, 8705, 9010, 9019, 9266, respectively). In lanes 7-9 HindIII digests of the genomic DNAs of the three BHV1 isolates from herd 33A have been separated $(7245,8719,8951$, respectively). Lane 10, HindIII digest of the Dutch BHV1 isolate Lam. Lane 11, HindIII digest of a BHV1 IPV strain 61169. Lane 12, HindIII digest of the temperature-sensitive BHV1 vaccine strain RBL106. (b) EcoRV digests of the genomic DNAs of the same BHV1 isolates as in $(a)$ have been separated. Lanes as in $(a)$. kb, kilobasepairs; ${ }^{\text {, }}$, animal-identification number.

Based on these data, a between-herd basic reproduction ratio of 0.6 was estimated $(95 \%$ confidence interval 0-3.79).

\section{DISCUSSION}

The objective of this study was to describe the transmission of BHV1 within and between herds. Because all cattle farms on the island were involved in a BHV1 control programme, the outbreaks of BHV1 infections could be monitored closely and the most likely origin of infections could be traced.
As evidenced by the absence of seroconversion in the susceptible herds of groups 1 and 2, BHV1 did not circulate within these herds during the 2-year period prior to the first BHV1 introduction.

In our study four (major) outbreaks were observed on the island. Other studies revealed that direct animal contacts (purchase, fence, escaping or mingling) are probably important risk factors for the introduction of BHV1 on farms [25, 26]. In this study, three of these outbreaks could be attributed to introduction of virus from outside the control programme area. Apparently, this was the major source of infectious 
material. Therefore, in the framework of eradication of BHV1, direct animal contacts with other cattle, not proven BHV1-free, should be avoided.

The source of BHV1 in one outbreak is unknown and the outbreak could be explained by reactivation of latent BHV1. If so, then there was only one case of reactivation causing transmission of infection in the 4 years of observation of 11 herds in which vaccinated seropositive cattle were present (group 2) and in the 3 years of observation of 20 herds in which virus was present and in which all cattle were vaccinated with a gD-subunit vaccine. This may indicate that in closed herds reactivation of virus in vaccinated cattle does not have a major role in causing an outbreak of BHV1 infections. In any case, accelerated cull of seropositive cattle will reduce the chance that a susceptible herd becomes infected and, therefore, will decrease BHV1 transmission between herds [14].

It has been reported that a BHV1-infected herd may be infectious for a 7-week period [5]. From the results of this study, it can be concluded that after the introduction of infectious cattle in susceptible herds, the infectious period of these herds may last up to 10 weeks.

Herd 33A was infected with three different BHV1 strains at the same time. As reported earlier, cattle can be infected with more than one BHV1 strain at the same time $[9,27,28]$. Therefore, the introduced seronegative heifer may itself have been infected with three different BHV1 strains. This is quite likely, because this heifer had been housed in close contact with many cattle from different herds from the mainland during the 2-week period prior to its introduction to herd 33A.

Virus introduction led to a major outbreak of BHV1 infections in all herds, and hence the within-herd reproduction ratio was substantially larger than 1 . The estimated $R_{0 \text {, within }}$ values are probably underestimations of the true $R_{0}$, within since the size of the last infectious generation that was present in the absence of susceptible cattle was unknown, due to the large sampling interval. If this information had been available, estimates of $R$ would have been substantially larger, and probably close to the previous estimate of approximately 7 [5].

However, the success of an area-wide eradication programme strongly depends on between-herd transmission [29]. Only one outbreak (1B) led to (three) secondary outbreaks in other herds. One of these secondary outbreaks (herd 33B) was most likely induced by human transmission, and another secondary outbreak (herd 55B) was probably caused by direct contact between animals. In the third secondary outbreak (herd 38), the cattle showed the first clinical signs of an IBR infection during the infectious period of herd 33A. These cattle (herd 38) were tied to the north wall of the barn next to an open window. The virus isolated from cattle of this herd (herd 38) showed the same DNA-REA fragment pattern as one of the isolates of herd 33A (Fig. 5). An extensive investigation did not reveal any evidence for transmission by cattle, other animal species, humans, or equipment. Because of (1) the geographical situation of these two herds (Fig. 1b), (2) the strong north-western wind for several days during the infectious period of the primary infected herd, (3) the time the first cattle showed clinical signs of IBR in this secondary outbreak and (4) the location of the first cattle with clinical signs of IBR, aerogenic transmission is not unlikely. Former experiments have shown that airborne transmission of BHV1 is possible between individual cattle in the same barn over a short distance [30]. Aerogenic transmission of BHV1 between herds over a relatively short distance [31] and over long distances [32] has been suggested before. However, in our study several BHV1 susceptible herds that did not become infected were located near the primary and secondary infected herds. Therefore, in these outbreaks aerogenic transmission did not have an important role in transmission of BHV1 between herds.

On the basis of our data, an infectious herd caused 0.6 new cases of infection in a completely susceptible population.

The proportion of susceptible herds in this study was about $50 \%$ of the total number of herds on the island. Because vaccinated herds are not as susceptible to outbreaks of BHV1 infections as nonvaccinated herds [16], the resulting $R_{0, \text { between }}$ should be interpreted accordingly (i.e. within a vaccinated population). Since the observation period per infected herd was limited (future reactivations may occur in these herds), the estimated $R_{0}$, between in this study is probably an underestimation.

During the 4 years of the BHV1 control programme, the number of BHV1-free herds did not change. A major reason was the number of large outbreaks in seronegative herds.

Despite high within-herd transmission, betweenherd transmission may be low in an area with an adequate control programme. Eradication of BHV1 depends on preventing the introduction of the virus, and on the amount of reactivation in herds. From our 
data, we conclude that introductions play an important role and that reactivation of vaccinated cattle is of limited importance.

\section{ACKNOWLEDGEMENTS}

The authors thank all cattle farmers on the island of Ameland, The Netherlands, for their cooperation, Fokke-Jan de Jong, Klaas de Haan, Hink-Jan Stel, Geert Alsma, Klaas-Siebe Broersma, Arjen van der Schaaf, and Rinus van Wijck for assistance during this study and Pfizer Animal Health for financial support.

\section{REFERENCES}

1. Gibbs EPJ, Rweyemamu MM. Bovine herpesviruses. Part I. Bovine herpesvirus 1. Vet Bull 1977; 47: 317-43.

2. Kahrs RF. Infectious bovine rhinotracheitis: a review and update. Am J Vet Med Assoc 1977; 171: 1055-64.

3. Lupton HW, Reed DE. Evaluation of experimental subunit vaccines for infectious bovine rhinotracheitis. Am J Vet Res 1980; 41: 383-90.

4. Van Oirschot JT, Straver PJ, Van Lieshout JAH, Quak J, Westenbrink F, Van Exsel ACA. A subclinical infection of bulls with bovine herpesvirus type 1 at an artificial insemination centre. Vet Rec 1993; 132: $32-5$.

5. Hage JJ, Schukken YH, Barkema HW, Benedictus G, Rijsewijk FAM, Wentink GH. Population dynamics of BHV1 infection in a dairy herd. Vet Microbiol 1996; 53: $169-80$.

6. Ackermann M, Peterhans E, Wyler R. DNA of bovine herpesvirus type 1 in the trigeminal ganglia of latently infected calves. Am J Vet Res 1982; 43: 36-40.

7. Chow TL. Duration of immunity in heifers inoculated with infectious bovine rhinotracheitis virus. J Am Vet Med Assoc 1972; 160: 51-4.

8. Dennett DP, Barasa JO, Johnson RH. Infectious bovine rhinotracheitis virus: studies on venereal carrier status in range cattle. Res Vet Sci 1976; 20: 77-83.

9. Kaashoek MJ, Moerman A, Madic J, et al. A conventionelly attenuated glycoprotein E-negative strain of bovine herpesvirus 1 is an efficacious and safe vaccine. Vaccine 1994; 12: 439-44.

10. Van Drunen Littel-van den Hurk S, Parker MD, et al. Protection of cattle from BHV-1 infection by immunization with recombinant glycoprotein gIV. Vaccine $1993 ; \mathbf{1 1}: 25-35$.

11. Bosch JC, Kaashoek MJ, Van Oirschot JT. Inactivated bovine herpesvirus 1 marker vaccines are more efficacious in reducing virus excretion after reactivation than a live marker vaccine. Vaccine $1997 ; 14: 1512-7$.

12. Anderson RM, May RM. Directly transmitted infectious diseases: Control by vaccination. Science 1982; 215: 1053-60.
13. Becker N. Analysis of infectious disease data. London: Chapman and Hall, 1989.

14. Hall R, Becker NG. Preventing epidemics in a community of households. Epidemiol infect 1996; 117: $443-55$.

15. Anderson RM, May RM. Modern vaccines: immunization and herd immunity. Lancet 1990; 335: 641-5.

16. Bosch JC, De Jong MC, Franken P, et al. An inactivated gE-negative marker vaccine and an experimental gD-subunit vaccine reduce the incidence of bovine herpesvirus 1 infections in the field. Vaccine 1998; 16: 265-71.

17. Pastoret P-P, Babiuk LA, Misra V, Griebel P. Reactivation of temperature-sensitive and non temperaturesensitive infectious bovine rhinotracheitis vaccine virus with dexamethasone. Infect Immunol 1980; 29: 483-8.

18. Kramps JA, Magdalena J, Quak J, et al. A simple, specific, and highly sensitive blocking enzyme-linked immunosorbent assay for detection of antibodies to bovine herpesvirus 1. J Clin Microbiol 1994; 32: 2175-81.

19. Brar JS, Johnson DW, Muscoplat CC, Shope RE, Meiske JC. Maternal immunity to infectious bovine rhinotracheitis and bovine viral diarrhoea viruses: duration and effect on vaccination in young calves. Am $\mathbf{J}$ Vet Res 1978; 39: 241-4.

20. Zygraich N, Lobmann M, Vascoboinic E, Berge E, Huygelen C. In vivo and in vitro properties of a temperature sensitive mutant of infectious bovine rhinotracheitis virus. Res Vet Sci 1974; 16: 328-35.

21. Hage JJ, Vellema P, Schukken YH, et al. Sheep do not have a major role in bovine herpesvirus 1 transmission. Vet Microbiol 1997; 57: 41-54.

22. Van Engelenburg FAC, Kaashoek MJ, Rijsewijk FAM, et al. A glycoprotein $\mathrm{E}$ deletion mutant of bovine herpesvirus 1 is avirulent in calves. J Gen Virol 1994; 75: 2311-8.

23. Van Oirschot JT, Rijsewijk FAM, Straver PJ, et al. The virulence and genotype of a bovine herpesvirus 1 isolate from semen of a subclinical infected bull. Vet Rec 1995; 137: 235-9.

24. Sambrook J, Fritsch EF, Maniatis T. Molecular cloning, a laboratory manual, 2nd edn. Cold Spring Harbor: Cold Spring Harbor Laboratory Press, 1989.

25. Van Schaik G, Schukken YH, Nielen M, Dijkhuizen AA, Benedictus G. Risk factors for introduction of BHV1 into BHV1-free Dutch diary farms: a case control-study. Vet Quarterly 2001; 23: 71-6.

26. Van Schaik G, Schukken YH, Nielen M, Dijkhuizen AA, Barkema HW, Benedictus G. Probability of and risk factors for introduction of infectious diseases into Dutch SPF dairy farms: a cohort study. Prev Vet Med 2002; 54: 279-89.

27. Thiry E, Brochier B, Saliki J, Pirak M, Pastoret P-P. Excretion and re-excretion of thermosensitive and wildtype strains of infectious bovine rhinotracheitis virus after co-infection or two successive infections. Vet Microbiol 1985; 10: 371-80. 
28. Whetstone CA, Miller JM. Two different strains of an alphaherpesvirus can establish latency in the same tissue of the host animal: evidence from bovine herpesvirus 1 . Arch Virol 1989; 107: 27-34.

29. Van Nes A, De Jong MCM, Buijtels JAAM, Verheijden JHM. Implications derived from a mathematical model for eradication of pseudorabies virus. Prev Vet Med 1998; 33: 39-58.

30. Mars MH, de Jong MC, van Maanen C, Hage JJ, van Oirschot JT. Airborne transmission of bovine herpesvirus 1 infections in calves under field conditions. Vet Microbiol 2000; 76: 1-13.

31. Janzen ED, Smart JN, Nicholson HH. Observations on an outbreak of infectious Bovine Rhinotracheitis in a bull test station. Can Vet J $1980 ; 21$ : 24-7.

32. Nylin B, Mortensen S, Henriksen CA, Rønsholt L, Laurids CS. Epidemiologiske og meteorologiske forhold omkring tilbagevendende nysmitte af kvæghesætninger 1 sønderjylland med IBR-virus. Dansk Veterinærtidsskrift $1995 ; \mathbf{7 8}: 821-7$. 